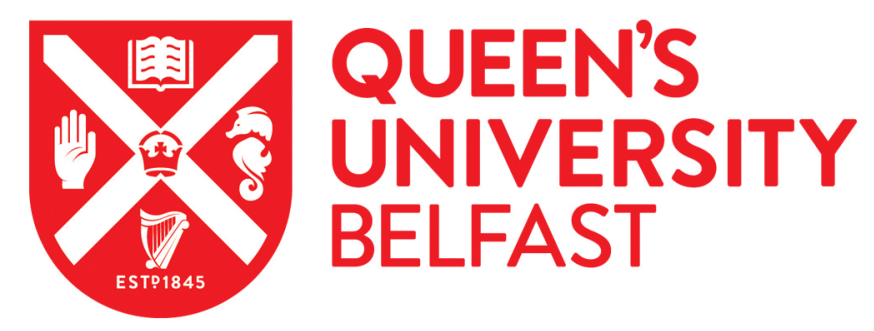

\title{
Catalytic and photocatalytic water gas shift reaction (WGSR) using a continuous flow, gas phase reactor
}

Bingham, M., \& Mills, A. (2021). Catalytic and photocatalytic water gas shift reaction (WGSR) using a continuous flow, gas phase reactor. Journal of Photochemistry and Photobiology A: Chemistry, 409, [113133].

https://doi.org/10.1016/j.jphotochem.2021.113133

Published in:

Journal of Photochemistry and Photobiology A: Chemistry

Document Version:

Peer reviewed version

Queen's University Belfast - Research Portal:

Link to publication record in Queen's University Belfast Research Portal

\section{Publisher rights}

Copyright 2021 Elsevier.

This manuscript is distributed under a Creative Commons Attribution-NonCommercial-NoDerivs License

(https://creativecommons.org/licenses/by-nc-nd/4.0/), which permits distribution and reproduction for non-commercial purposes, provided the author and source are cited.

\section{General rights}

Copyright for the publications made accessible via the Queen's University Belfast Research Portal is retained by the author(s) and / or other copyright owners and it is a condition of accessing these publications that users recognise and abide by the legal requirements associated with these rights.

Take down policy

The Research Portal is Queen's institutional repository that provides access to Queen's research output. Every effort has been made to ensure that content in the Research Portal does not infringe any person's rights, or applicable UK laws. If you discover content in the Research Portal that you believe breaches copyright or violates any law, please contact openaccess@qub.ac.uk. 


\title{
Catalytic and Photocatalytic water gas shift reaction (WGSR) using a continuous flow, gas phase reactor.
}

\author{
Michael Bingham and Andrew Mills* \\ ${ }^{*}$ School of Chemistry and Chemical Engineering, Queens University Belfast, David Keir \\ Building, Stranmillis Road, Belfast, BT9 5AG, UK \\ e-mail: andrew.mills@qub.ac.uk
}

\begin{abstract}
A series of different $\mathrm{M} / \mathrm{TiO}_{2}$ catalysts are prepared, where $\mathrm{M}=\mathrm{Au}, \mathrm{Pt}, \mathrm{Pd}$ and $\mathrm{Ag}$, with a 0.2 wt\% loading, and tested for activity as catalysts and photocatalysts for the water gas shift reaction, WGSR, using a continuous flow, gas phase reactor. For both the thermal (dark) and photocatalytic (UV irradiated) WGSR the best catalyst/photocatalyst is $\mathrm{Au} / \mathrm{TiO}_{2}$. The kinetics of the WGSR is studied as a function of reactor temperature, Au loading and concentrations of $\mathrm{CO}$ and $\mathrm{H}_{2} \mathrm{O}$. Langmuir-Hinshelwood kinetics are observed for the photocatalytic WGSR with non-competitive adsorption of the $\mathrm{CO}$ and $\mathrm{H}_{2} \mathrm{O}$, whereas those for the thermal WGSR fit a slightly more complex, previously reported, reaction mechanism. At $125^{\circ} \mathrm{C}$, with a $0.2 \mathrm{wt} \%$ loading, the $\mathrm{Au} / \mathrm{TiO}_{2}$ photocatalysis of the WGSR is very efficient, with a formal quantum efficiency for $1 / 2 \mathrm{H}_{2}$ production of $57 \%$. The potential scale up of the relatively efficient photocatalytic WGSR is discussed briefly.
\end{abstract}

Key words: water gas shift; carbon monoxide; catalysis; photocatalysis; titanium dioxide; gold. 


\section{Introduction}

Hydrogen is a much needed chemical feedstock, especially for ammonia production, which is an essential component in the industrial manufacture of fertilizers [1]. In addition, hydrogen is emerging as an important potential fuel for the future, in which an hydrogen economy is established, i.e. one in which hydrogen, rather than hydrocarbons, is used to provide power for transport and homes $[2,3]$. Much of the world's hydrogen is produced via steam reforming of natural gas [3], with additional hydrogen being generated from the reaction of water and CO, i.e. the water-gas shift reaction (WGSR), [4]:

$$
\mathrm{CO}+\mathrm{H}_{2} \mathrm{O} \stackrel{\Delta}{\longrightarrow} \mathrm{CO}_{2}+\mathrm{H}_{2}
$$

Almost all ammonia and oil refinery hydrogen plants have a low temperature stage (150-250 ${ }^{\circ} \mathrm{C}$ ) for driving the above reaction, usually using a $\mathrm{Cu} / \mathrm{ZnO}$ catalyst [5]. Noble metals can also be used as catalysts for reaction (1), although Pt is rather low in activity, due to the formation of a passivating surface layer of oxide, at these low temperatures. In contrast, and perhaps not surprisingly, under these same conditions, $\mathrm{Au}$ is the most active of the noble metals, and much more active than the traditional $\mathrm{Cu} / \mathrm{ZnO}$ catalyst noted above, especially when deposited on a $\mathrm{TiO}_{2}$ support [6]. Although a $\mathrm{Au} / \mathrm{TiO}_{2}$ catalyst for reaction (1) deactivates over time, its activity can be readily restored by flowing air over the catalyst at elevated temperatures [6].

Semiconductor photocatalysis can be used to effect a wide range of different reactions at low temperatures, with $\mathrm{TiO}_{2}$ being the semiconductor of choice, as it is abundant, inexpensive and photocatalytically very active [7]. One such reaction is the WGSR, although a metal cocatalyst also needs to be present, i.e. $\mathrm{M} / \mathrm{TiO}_{2}$, where $\mathrm{M}$ is usually a noble metal [8-13], i.e.

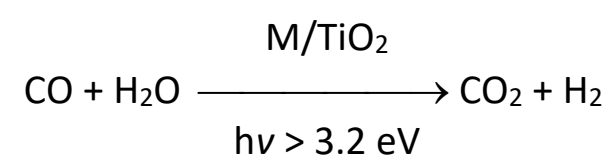

In the 1980's, work carried out by the various research groups [8-13] on the photocatalytic WGSR, i.e. reaction (2), focussed on using $\mathrm{M} / \mathrm{TiO}_{2}$, where $\mathrm{M}=\mathrm{Pt}$ or $\mathrm{Pd}$, usually using a batch reactor with a circulating gas phase and run at low temperatures, i.e. between $30-60^{\circ} \mathrm{C}$ [813]. As reported by Sato et al. [12] in their study of the photocatalytic WGSR, i.e. reaction (2), no hydrogen is produced with just $\mathrm{TiO}_{2}$ thereby highlighting the importance of the metal cocatalyst. 
Sato and his co-workers have proposed a simple, commonly used, flux-matching model as the basis of the reaction mechanism for the photocatalysed WGSR by their $\mathrm{M} / \mathrm{TiO}_{2}$ photocatalysts, in which an electron-hole pair is formed upon ultra-bandgap irradiation [12], i.e.

$$
\mathrm{TiO}_{2} \stackrel{\mathrm{UV}}{\longrightarrow} \mathrm{TiO}_{2}\left(\mathrm{~h}^{+}, \mathrm{e}^{-}\right)
$$

and the photogenerated electrons are drawn to the metal co-catalyst, which mediates the reduction of $\mathrm{H}_{2} \mathrm{O}$ to $\mathrm{H}_{2}$ :

$$
2 \mathrm{e}^{-}+2 \mathrm{H}^{+} \stackrel{\mathrm{Pt}}{\longrightarrow} \mathrm{H}_{2}
$$

while the photogenerated holes oxidise the $\mathrm{CO}$ to $\mathrm{CO}_{2}$ on the $\mathrm{TiO}_{2}$ substrate:

$$
\mathrm{H}_{2} \mathrm{O}+\mathrm{CO}+2 \mathrm{~h}^{+} \longrightarrow \mathrm{CO}_{2}+2 \mathrm{H}^{+}
$$

Since the 1980's there have been few reports on the photocatalytic WGSR [14] that is until Bowker et al. [15] in 2002, studied the activity of $\mathrm{Pd} / \mathrm{TiO}_{2}$ and found the reaction rate peaked at a $0.5 \mathrm{wt} \%$ loading and was zero at $2 \mathrm{wt} \%$. The most recent study of the photocatalysed WGSR, i.e. reaction (2), is that of Sastre et. al. [16], carried out using a batch reactor at room temperature, which showed that an $\mathrm{Au} / \mathrm{TiO}_{2}$ photocatalyst was much more active than $\mathrm{Pd} / \mathrm{TiO}_{2}[17]$.

Table 1 summarises the major features of most of the published reports on the WGSR photocatalysed by $\mathrm{M} / \mathrm{TiO}_{2}$ photocatalysts $[8-13,15,16]$, a brief inspection of which reveals no studies of the reaction in a continuous gas flow system, nor at a temperature $>60^{\circ} \mathrm{C}$. A continuous gas flow system is more industrially relevant since, for the majority of applications, it usually saves time and energy, and so cost [18], especially as flow systems are more easily scaled up for industrial production than batch systems [19]. To date, little attempt has been made to optimise the performance, or probe the kinetics, of the $\mathrm{M} / \mathrm{TiO}_{2}$ photocatalysed WGSR and this lack of detail is addressed here in a study of reaction (2) using a continuous flow system, where $\mathrm{M}=$ the noble metals: $\mathrm{Pt}, \mathrm{Pd}, \mathrm{Au}$ and $\mathrm{Ag}$. In particular, the kinetics exhibited by the best of the photocatalysts tested (i.e. $\mathrm{Au} / \mathrm{TiO}_{2}$ ) is studied as a function of the key reaction parameters: temperature, metal loading, $\mathrm{CO}$ and $\mathrm{H}_{2} \mathrm{O}$ concentration. 
Table 1: Brief details of previous studies of the WGSR photocatalysed by $\mathrm{M} / \mathrm{TiO}_{2}$

\begin{tabular}{|c|c|c|c|c|c|c|c|c|}
\hline Metal/TiO 2 & Wt.\% & $\mathrm{TiO}_{2}$ & Deposition & Temp $\left({ }^{\circ} \mathrm{C}\right)$ & Reactor & Light Source & $* \delta(\%)$ & Ref \\
\hline None, Pt & 2 & Anatase & Photolysis & $0-60$ & $\begin{array}{l}0.25 \mathrm{~g} \text { of catalyst used in a gas } \\
\text { phase reactor. }\end{array}$ & $\begin{array}{l}200 \mathrm{~W} \mathrm{Hg} \text { lamp ( } 275 \mathrm{~nm}, 380 \mathrm{~nm} \\
\text { and } 415 \mathrm{~nm} \text { cut-off filters used in a } \\
\text { wavelength dependence study). }\end{array}$ & 7 & $\begin{array}{l}{[13,} \\
14]\end{array}$ \\
\hline Pt & 2 and 10 & Anatase & $\begin{array}{l}\text { Photodeposition } \\
\text { and impregnation }\end{array}$ & 27 & $\begin{array}{l}0.2 \mathrm{~g} \text { of catalyst used while water } \\
\text { vapour and CO were circulated }\end{array}$ & $\begin{array}{l}200 \mathrm{~W} \text { Hg lamp }\left(0.21 \mathrm{~W} \mathrm{~cm}^{-2} \text { at }\right. \\
100 \%)\end{array}$ & $<5$ & [11] \\
\hline Pt & 1.5 & Anatase & Photodeposition & $30-60$ & $\begin{array}{l}0.2 \mathrm{~g} \text { of catalysts used in the gas } \\
\text { phase and } 0.1 \mathrm{~g} \text { of catalyst used in } \\
\text { the liquid phase. Gas phase; } \\
\text { recirculation glass device. Liquid } \\
\text { phase; agitated suspension. }\end{array}$ & 400 W high pressure Hg lamp. & - & [12] \\
\hline Pt & 1 and 5 & $\begin{array}{l}\mathrm{TiO}_{2} \\
\text { Anatase } \\
\text { and P25 }\end{array}$ & photodeposition & 60 & $\begin{array}{l}0.2 \mathrm{~g} \text { in a circulating gas phase } \\
\text { chamber }\end{array}$ & 200 W Hg lamp (10 mW cm $\left.{ }^{-2}\right)$ & - & $\begin{array}{l}{[9,} \\
10]\end{array}$ \\
\hline $\mathrm{Pd}$ & $\begin{array}{l}0.01,0.1 \\
0.5,1 \text { and } \\
2\end{array}$ & P25 & $\begin{array}{l}\text { Incipient } \\
\text { wetness. }\end{array}$ & 35 & $\begin{array}{l}0.2 \mathrm{~g} \text { of catalyst and } 100 \mathrm{~mL} \\
\text { deionised water with various } \\
\text { amounts of CO injected into the } \\
\text { headspace. }\end{array}$ & $\begin{array}{l}400 \text { W Xe arc lamp (Pyrex vessel cut } \\
\text { off wavelengths below } 300 \mathrm{~nm} \text { ). }\end{array}$ & - & [16] \\
\hline $\begin{array}{l}\mathrm{Pt}, \mathrm{Pd}, \mathrm{Cu}, \\
\mathrm{Au}, \mathrm{Ag}\end{array}$ & 1 & P25 & $\begin{array}{l}\text { Deposition/preci } \\
\text { pitation and } \\
\text { impregnation }\end{array}$ & 42 & $\begin{array}{l}\text { Pelletized catalyst } 1 \times 1.5 \mathrm{~cm}^{2} \\
\text { covered the surface of the gas } \\
\text { phase reactor containing moist } \\
\text { saturated } \mathrm{N}_{2} \text { and } \mathrm{CO} \text {. }\end{array}$ & $\begin{array}{l}\text { Solar light irradiation using an Oriel } \\
\text { solar simulator }\left(1 \mathrm{~kW} \mathrm{~cm}^{-2}\right) \text { with an } \\
\text { AM1.5 filter. Visible light irradiation } \\
\text { carried out using a } 450 \mathrm{~nm} \text { LED } \\
\text { lamp. }\end{array}$ & - & [17] \\
\hline
\end{tabular}

$* \delta=$ formal quantum efficiency for $1 / 2 \mathrm{H}_{2}$ production 


\section{Experimental}

\subsection{Materials declaration.}

Unless otherwise stated, all chemicals were purchased from Sigma Aldrich and used as received. The Aeroxide $\mathrm{P} 25 \mathrm{TiO}_{2}$ powder was a gift from Evonik (formerly Degussa). All gases were purchased from BOC and certified to be of $99.999 \%$ purity.

\subsection{Photocatalyst preparation.}

All $\mathrm{M} / \mathrm{TiO}_{2}$ photocatalysts, where $\mathrm{M}=\mathrm{Au}, \mathrm{Pt}, \mathrm{Pd}$, and $\mathrm{Ag}$, were prepared using the incipient wetness method [20-24]. Thus, for a typical photocatalyst $\mathrm{Au} / \mathrm{TiO}_{2}(0.2 \mathrm{wt} \%), 40 \mathrm{mg}$ of the metal salt $\left(\mathrm{HAuCl}_{4} \cdot 3 \mathrm{H}_{2} \mathrm{O}\right)$ were dissolved in $80 \mathrm{~cm}^{3}$ of water and the resulting solution added dropwise to $10 \mathrm{~g}$ of the $\mathrm{P} 25 \mathrm{TiO}_{2}$ powder. This aqueous dispersion was agitated continuously to produce a slurry which was left to dry overnight in an oven at $110^{\circ} \mathrm{C}$. The residual powder was then ground using a pestle and mortar and calcined at $500^{\circ} \mathrm{C}$ for $2 \mathrm{~h}$ before being sieved to an aggregated particle size between $250-400 \mu \mathrm{m}$. The Au salt coating the $\mathrm{TiO}_{2}$ powder particles was then reduced to the metal in a stream of hydrogen $\left(50 \mathrm{~cm}^{3} \mathrm{~min}^{-1}\right)$ in a tubular furnace at $200{ }^{\circ} \mathrm{C}$ for $2 \mathrm{~h}$ thereby yielding a $0.2 \mathrm{wt} \% \mathrm{Au} / \mathrm{TiO}_{2}$ photocatalyst. This method was also used to produce other 0.2 wt\% $\mathrm{M} / \mathrm{TiO}_{2}$ photocatalysts using the metal salts: $\mathrm{H}_{2} \mathrm{PtCl}_{6} .6 \mathrm{H}_{2} \mathrm{O}, \mathrm{PdCl}_{2}$ and $\mathrm{AgNO}_{3}$. For the $\mathrm{Au} / \mathrm{TiO}_{2}$ photocatalyst, various metal loadings of $\mathrm{Au} / \mathrm{TiO}_{2}(0.01,0.1,0.2,0.5$, and $1 \mathrm{wt} \%)$ were produced by altering the amount of metal salt used (i.e. 2, 20, 40, 101, and $202 \mathrm{mg}$, respectively).

\subsection{Photocatalyst characterisation.}

The weight loading of each photocatalyst was confirmed using an Inductively Coupled PlasmaOptical Emission Spectrometer, ICP-OES, (Agilent, 5110). The photocatalyst powders were also analysed using: (i) X-ray powder diffraction, XRD, (Panalytical, X'Pert) to confirm the crystalline structure of the $\mathrm{TiO}_{2}$ and (ii) Brunauer-Emmett-Teller, BET, (Micrometrics, Tristar 3020) for surface area assessment. From these studies, the $\mathrm{TiO}_{2}$ appeared to be an $80: 20 \mathrm{mix}$ of anatase and rutile with a specific area of ca. $50 \mathrm{~m}^{2} \mathrm{~g}^{-1}$, both before and after metal deposition and annealing. Additionally, the samples were analysed using a Transmission Electron Microscopy, TEM, (Jeol, JEM-1400), which revealed an average $\mathrm{TiO}_{2}$ particle radius for the P25 powder of ca. $15 \mathrm{~nm}$. The Au particle radii for a $0.2 \mathrm{wt} \%$, and $1 \mathrm{wt} \%, \mathrm{Au} / \mathrm{TiO}_{2}$ photocatalyst were estimated to be 2.0 , and $4 \mathrm{~nm}$, respectively, from many TEM images, such as illustrated in Fig. 1 below. 

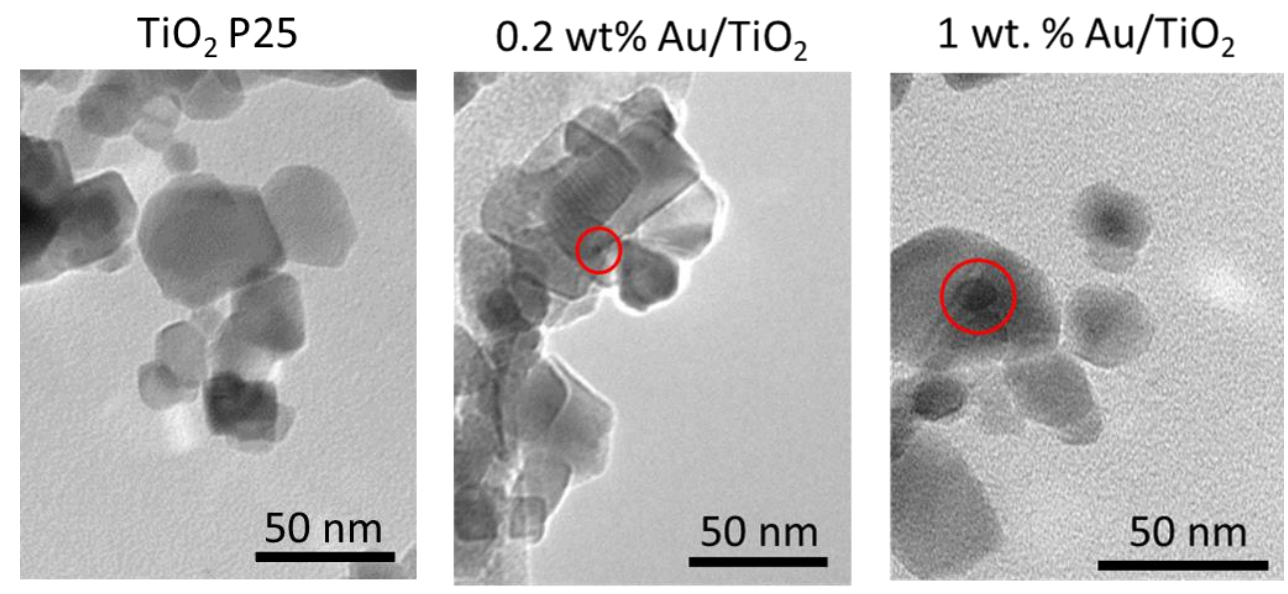

Fig. 1: Typical TEM micrographs of $\mathrm{P} 25,0.2 \mathrm{wt} \% \mathrm{Au} / \mathrm{TiO}_{2}$ and $1 \mathrm{wt} \% \mathrm{Au} / \mathrm{TiO}_{2}$ where the average Au particle sizes (radius) is revealed to be, N/A, 2.0 and $4 \mathrm{~nm}$ respectively. Note: The average $\mathrm{Au}$ particle size was measured from various particles identified using many TEM micrographs.

Other TEM studies on the $0.2 \mathrm{wt} \% \mathrm{M} / \mathrm{TiO}_{2}$ photocatalysts, where $\mathrm{M}=\mathrm{Pt}, \mathrm{Pd}$ and $\mathrm{Ag}$, showed metal particle radii of: $0.5,3$ and $1.5 \mathrm{~nm}$, respectively [24].

As illustrated in Fig. 2(a), digital photographic images were recorded for the $\mathrm{Au} / \mathrm{TiO}_{2}$ photocatalysts and show a transition from light violet to a deep dark blue as the metal loading was increased from $0.01 \mathrm{wt} \%$ to $1 \mathrm{wt} \%$. Fig 2(b) shows digital photographic images of Pt, Pd and $\mathrm{Ag} 0.2 \mathrm{wt} \% \mathrm{M} / \mathrm{TiO}_{2}$ photocatalysts which were dark grey, light grey and dark red/brown, respectively.

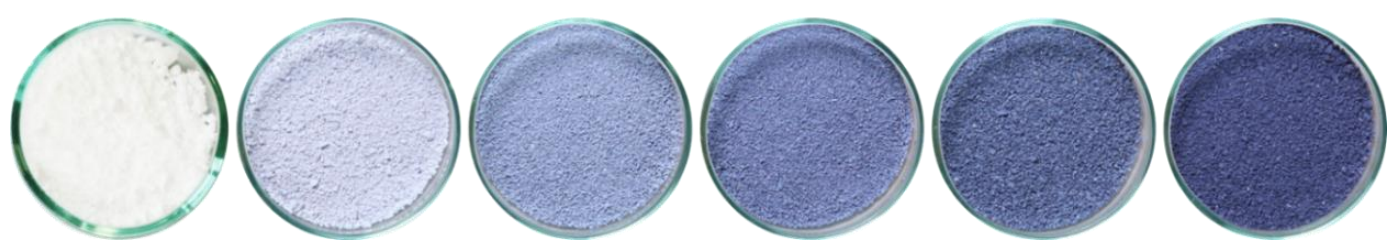

(a)
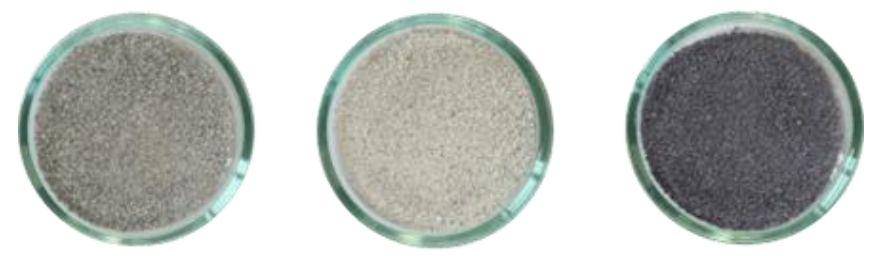

(b)

Fig. 2: (a) Digital images of various $\mathrm{Au} / \mathrm{TiO}_{2}$ photocatalysts with 0 to $1 \mathrm{Wt} \% \mathrm{Au}$ loading (from left to right; $0,0.01,0.1,0.2,0.5$, and 1 wt\%) and (b) Digital images for $0.2 \mathrm{wt} \% \mathrm{Pt}, \mathrm{Pd}$ and $\mathrm{Ag} / \mathrm{TiO}_{2}$ photocatalysts (from left to right). 


\subsection{Thermal and photocatalytic activity testing in the gas phase.}

The kinetics of reactions (1) or (2), catalysed or photocatalysed, respectively, by various $\mathrm{M} / \mathrm{TiO}_{2}$ powders $(\mathrm{M}=\mathrm{Au}, \mathrm{Pd}, \mathrm{Pt}$ and $\mathrm{Ag}$ ), were studied using a continuous flow, gas phase photoreactor system, the details of which have been described elsewhere $[18,23,24]$ and an illustration of which is given in the labelled schematic in Fig. S1, in the electronic supplementary information, i.e. ESI, section. In a typical run, $2.4 \mathrm{~g}$ of the photocatalyst powder under test were placed into a serpentine 'S-bend' borosilicate glass reactor with internal and external diameters of $3.75 \mathrm{~mm}$ and $6 \mathrm{~mm}$, respectively, see Figs. S1 and S2 in the ESI. The catalyst was held in place using two plugs of glass wool at the top and bottom of the serpentine, and the reactor was inserted into the main body of the heated flow reactor. UV irradiation of the serpentine glass reactor was carried out by using a $10 \mathrm{~W}, 365 \mathrm{~nm}$ narrowband UVA LED (RS Components, LZ1-10UV00) with an irradiance of $9.5 \mathrm{~mW} \mathrm{~cm}^{-2}$. Typically, the reaction was run at ca. $125^{\circ} \mathrm{C}$, unless stated otherwise with the reactor temperature set and controlled by a semi-cylindrical ceramic fibre heater.

In a typical run, a stream of $\mathrm{Ar}$, containing: $\mathrm{H}_{2} \mathrm{O}$ vapour ( $10 \%$ by volume) and $\mathrm{CO}(10 \%$ by volume), was passed over the catalyst/photocatalyst for $4 \mathrm{~h}$, at a flow rate of $10 \mathrm{~cm}^{3} \mathrm{~min}^{-1}$. The initial $1.25 \mathrm{~h}$ of a run was carried out in the dark, during which the $\mathrm{M} / \mathrm{TiO}_{2}$ powder under test was assessed as a thermal catalyst of reaction (1), after that the glass reactor was UV irradiated for $1.5 \mathrm{~h}$, thereby testing the $\mathrm{M} / \mathrm{TiO}_{2}$ powder as a photocatalyst of reaction (2), and then, finally, the system was returned to the dark for the final $1.25 \mathrm{~h}$ of the run, in order to demonstrate that the photocatalytic response was reversible and that the observed thermal catalytic activity was restorable. The \% (v/v) levels of $\mathrm{H}_{2}$ and $\mathrm{CO}$ in the gas stream, $\left[\mathrm{H}_{2}\right]$ and [CO], respectively, were determined using gas chromatography, with the gas stream sampled every $0.5 \mathrm{~h}$ during the $4 \mathrm{~h}$ period of a typical reaction run. The gas chromatograph used was a Perkin Elmer, Clarus Arnel 580 GC fitted with a Porapak D column with a TCD, for analysis of $\mathrm{H}_{2}$ and an FID-methaniser for the analysis of $\mathrm{CO}_{2}$. The values of $\left[\mathrm{H}_{2}\right]$ and $\left[\mathrm{CO}_{2}\right]$ (units: \%) measured by GC at any time, $t$, during a run were converted to values for the rate of the WGSR, i.e. $r\left(\mathrm{H}_{2}\right)$ and the $r\left(\mathrm{CO}_{2}\right)$, respectively (units: $\mathrm{mol} \mathrm{h}^{-1}$ ) using the following expression:

$$
r\left(\mathrm{H}_{2} \text { or } \mathrm{CO}_{2}\right)=\left[\mathrm{H}_{2}\right]\left(\operatorname{or}\left[\mathrm{CO}_{2}\right]\right) \cdot f . \mathrm{P} / 100 \mathrm{RT}
$$


where, $\mathrm{T}$ is the sampled gas temperature (typically $292.5 \mathrm{~K}$ ) and $f$ is the gas flow rate (typically, $10 \mathrm{~cm}^{3} \mathrm{~min}^{-1}$, i.e. $\left.60 \times 10^{-5} \mathrm{~m}^{3} \mathrm{~h}^{-1}\right)$. Eqn (6) was used throughout this work to covert the $\left[\mathrm{H}_{2}\right]$ and [CO] values to $r\left(\mathrm{H}_{2}\right)$ and $r(\mathrm{CO})$ values. A typical resulting plot of $r\left(\mathrm{H}_{2}\right)$ and the $r\left(\mathrm{CO}_{2}\right)$, versus reaction time is illustrated in Fig. 3 , and further details as to how this was constructed from the original measured $\% \mathrm{H}_{2}$ and $\% \mathrm{CO}_{2}$ values are given in section $\mathrm{S} 3$ of the ESI.

A typical example of the observed variation in rate for a 0.2 wt\% $\mathrm{Au} / \mathrm{TiO}_{2}$ catalyst/photocatalyst with time profile run at $125^{\circ} \mathrm{C}$, before, during and after UV irradiation, is illustrated in Fig. 3. These results show that, when using a $0.2 \mathrm{wt} \% \mathrm{Au} / \mathrm{TiO}_{2}$ catalyst/photocatalyst, both reaction (1) (the dark, thermal catalytic WGSR) and reaction (2) (the UV driven photocatalytic WGSR) produce equal amounts of $\mathrm{H}_{2}$ and $\mathrm{CO}_{2}$, as expected. This feature was exhibited by all the catalysts/photocatalysts tested in this work and indicates the major reactions that take place on the $\mathrm{M} / \mathrm{TiO}_{2}$ catalysts/photocatalysts are well described by reactions (1) and/or (2), in the absence and presence of UV illumination, respectively.

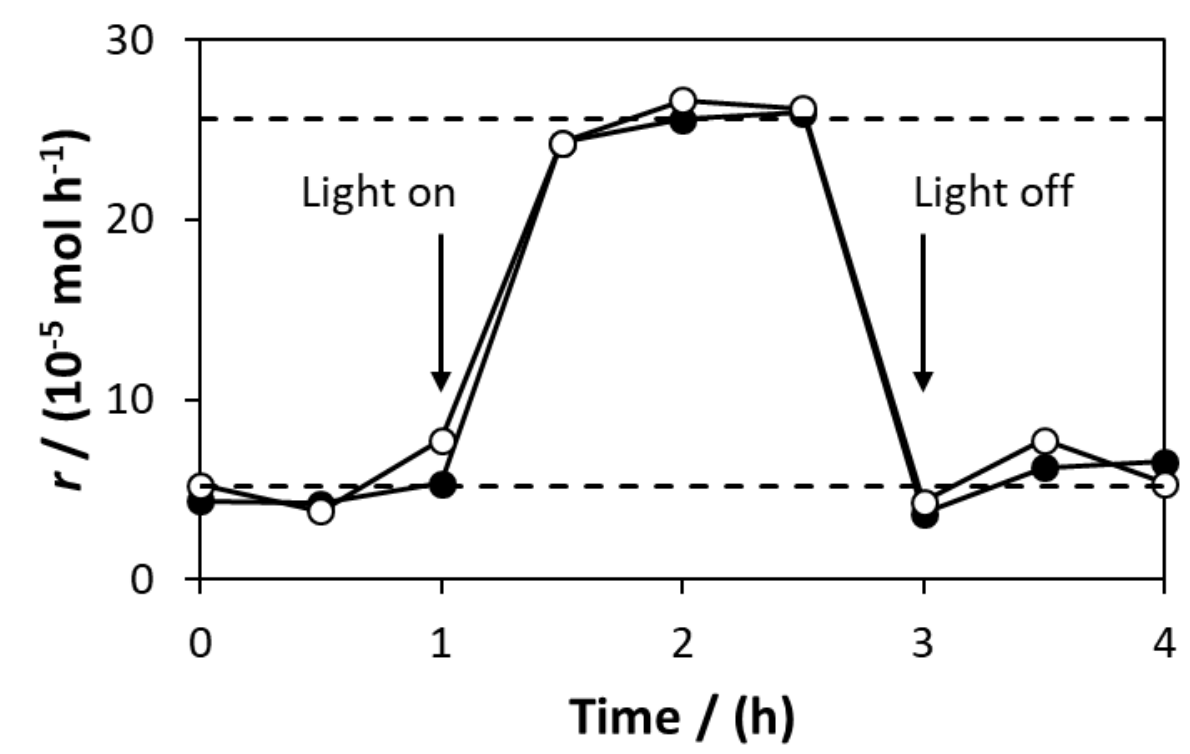

Fig. 3: A typical example of light off, light on, light off cycle, carried out at $125^{\circ} \mathrm{C}$ using a 0.2 wt\% $\mathrm{Au} / \mathrm{TiO}_{2}$ catalyst. Here the production of $\mathrm{H}_{2}$ (white circles) and $\mathrm{CO}_{2}$ (black circles) with the average $r\left(\mathrm{H}_{2}\right)$ reported for dark and UV conditions, 5.2 and $25.6\left(10^{-5} \mathrm{~mol} \mathrm{~h}^{-1}\right)$ respectively, are highlighted by broken horizontal lines. 


\section{Results and discussion}

\subsection{Au and other metals as $M$}

In an initial study of the thermal reaction (1), and photocatalytic reaction (2), i.e. the two versions of the WGSR mediated by $\mathrm{M} / \mathrm{TiO}_{2}$ and studied here, a series of different metals were tested, namely with $\mathrm{M}=\mathrm{Au}, \mathrm{Pt}, \mathrm{Pd}$ and $\mathrm{Ag}$, and a loading of $0.2 \mathrm{wt} \%$ and a reactor temperature of $125{ }^{\circ} \mathrm{C}$. The results of the study of the variation in the rates of reactions (1) and (2) as a function of metal co-catalyst, M, are illustrated in Fig. 4, in the form of a histogram plot of $r\left(\mathrm{H}_{2}\right)$ vs metal co-catalyst, and reveals that the photocatalytic reaction rate was always much greater (typically $6 x^{\prime} s$ ) that of the thermal (i.e. dark) reaction, regardless of the metal, and no thermal or photocatalytic reaction takes place in the absence of $\mathrm{M}$.

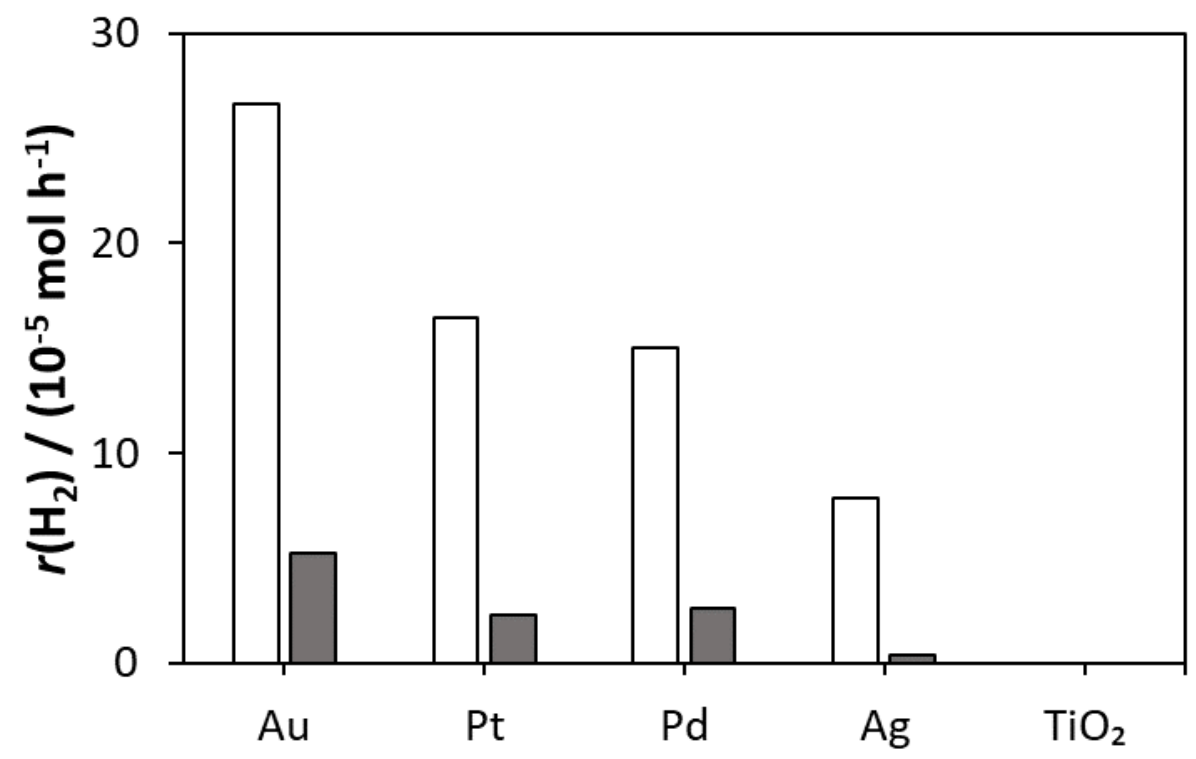

Fig. 4: Histogram plot of $r\left(\mathrm{H}_{2}\right)$ vs metal type recorded using a series of different $\mathrm{M} / \mathrm{TiO}_{2}, 0.2$ wt\% loading, in the WGSR reactor at $125^{\circ} \mathrm{C}$, with UV light off (grey shaded boxes) and on, 365 $\mathrm{nm}, 9.5 \mathrm{~mW} \mathrm{~cm}^{-2}$ (unshaded boxes).

The results illustrated in Fig. 4 show that the trends in activities for the thermal and the photocatalytic WGS reactions as a function of the metal deposited are very similar, if not the same, with $\mathrm{Au}$ and $\mathrm{Ag}$ the most and least active, respectively, and Pt and Pd similar and of an intermediate activity. This is perhaps not too surprising given the similarities in reaction mechanism for the two processes, reactions (1) and (2). Thus, the reaction mechanism for the photocatalytic WGSR, reaction (2), involves adsorbed $\mathrm{OH}$ radical formation ( $v i a \mathrm{~h}^{+}+\mathrm{H}_{2} \mathrm{O}_{\text {ads }}$ 
$\longrightarrow \mathrm{OH}_{\text {ads }}+\mathrm{H}^{+}$) and the subsequent reaction of $\mathrm{OH}_{\text {ads }}$ with $\mathrm{CO}_{\text {ads }}$ to form $\mathrm{CO}_{2}$, as summarised by reaction (5). Hydrogen formation occurs on the metal via the initial formation of adsorbed $\mathrm{H}$ radicals $\left(\mathrm{e}^{-}+\mathrm{H}^{+} \longrightarrow \mathrm{H}_{\text {ads }}\right.$ ) which then combine to form $\mathrm{H}_{2}$, as summarised by reaction (4). Similar features are present in the reported mechanism for the thermal (dark) WGSR, i.e. reaction (1), which is summarised below [25], i.e.

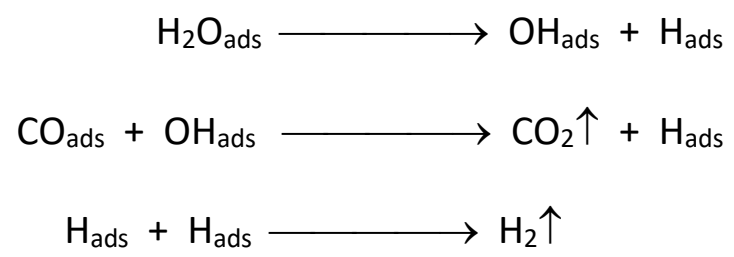

with reaction (7) occurring on the oxide (at $\mathrm{O}$ vacancies), CO adsorption on nearby gold particles and all other steps at the oxide-metal interface [25].

It follows that in both mechanisms, the rate of reaction will depend upon a number of different features of the metal, such as work function, $\mathrm{CO}$ heat of adsorption, $\mathrm{M}-\mathrm{H}$ bond strength, as well as the radius of the metal particles. The values of these different parameters for the metals used here are listed in Table S1 in section S4, in the ESI and only the M-H bond strength appears to show any clear correlation with observed rate, as illustrated by Fig. S5 in section S4. However, little can be taken from this apparent correlation given the concomitant significant variation in all the other parameters, in particular metal particle radius, which will have a significant impact on rate.

Finally, given our knowledge of: the value of $r\left(\mathrm{H}_{2}\right)$ (units: moles of $\mathrm{H}_{2} \mathrm{~h}^{-1}$ ) for reaction (2) for each $\mathrm{M} / \mathrm{TiO}_{2}$ photocatalyst, the irradiance $\left(9.5 \mathrm{~mW} \mathrm{~cm}^{-2}, 365 \mathrm{~nm}\right.$ ), the irradiation area (of the serpentine reactor, $A=8.9 \mathrm{~cm}^{2}$ ), then the formal quantum efficiency for each of the $\mathrm{M} / \mathrm{TiO}_{2}$ photocatalysts for the generation of $1 / 2 \mathrm{H}_{2}$, i.e. $\delta$, can be calculated, using the following expression,

$$
\delta=2 \times r\left(\mathrm{H}_{2}\right) \times N_{A} /\left(9.5 \times 1.84 \times 10^{15} \times A \times 3600\right)
$$

given $1 \mathrm{~mW} \mathrm{~cm}{ }^{-2}$ of $365 \mathrm{~nm}$ radiation $\equiv 1.84 \times 10^{15}$ photons $\mathrm{cm}^{-2} \mathrm{~s}^{-1}$ and $\mathrm{N}_{\mathrm{A}}=$ Avogadro's constant. Using the rate data contained in Fig. 4 and eqn (10) the following values of $\delta$ were calculated for the $\mathrm{M} / \mathrm{TiO}_{2}$ photocatalysed WGSR, of $0.57,0.35,0.32$ and 0.17 , where $\mathrm{M}=\mathrm{Au}$, $\mathrm{Pt}, \mathrm{Pd}$ and $\mathrm{Ag}$, respectively. These values reveal that the WGSR photocatalysed by $\mathrm{Au} / \mathrm{TiO}_{2}$ in particular is a very efficient process (57\%) which is ca. 10 times greater than that reported 
previously $[11,13,14]$, although in the latter work $\mathrm{M}=\mathrm{Pt}$ and the reaction was conducted at a much lower temperature, see Table 1. The rate data reported by Sastre et al [16] in their study of the same system but carried out in a batch reactor at room temperature, when treated in the same way, reveals $\delta$ values of $0.36,0.14,0.14$ and 0.06 for $\mathrm{M}=\mathrm{Au}, \mathrm{Pt}, \mathrm{Pd}$ and $\mathrm{Ag}$, respectively. In both cases it seems likely a component (ca. $20 \%$ in the case of the $\mathrm{Au} / \mathrm{TiO}_{2}$ photocatalyst/catalyst used here; see Fig. 4) of the overall measured rate of $\mathrm{H}_{2}$ generation used in the above calculation is due to thermal catalysis, i.e. reaction (1), but, even if this is taken into account, the formal quantum efficiency for the $\mathrm{Au} / \mathrm{TiO}_{2}$ photocatalyst is still very high ( $\delta=$ ca. 0.46 here).

\subsection{Temperature}

The rates of reaction, $r\left(\mathrm{H}_{2}\right)$, were determined for the thermal and photocatalytic versions of the WGSR using the $\mathrm{Au} / \mathrm{TiO}_{2}$ powder over the temperature range $75-175{ }^{\circ} \mathrm{C}$ and the results of this work are illustrated in Fig. 5.

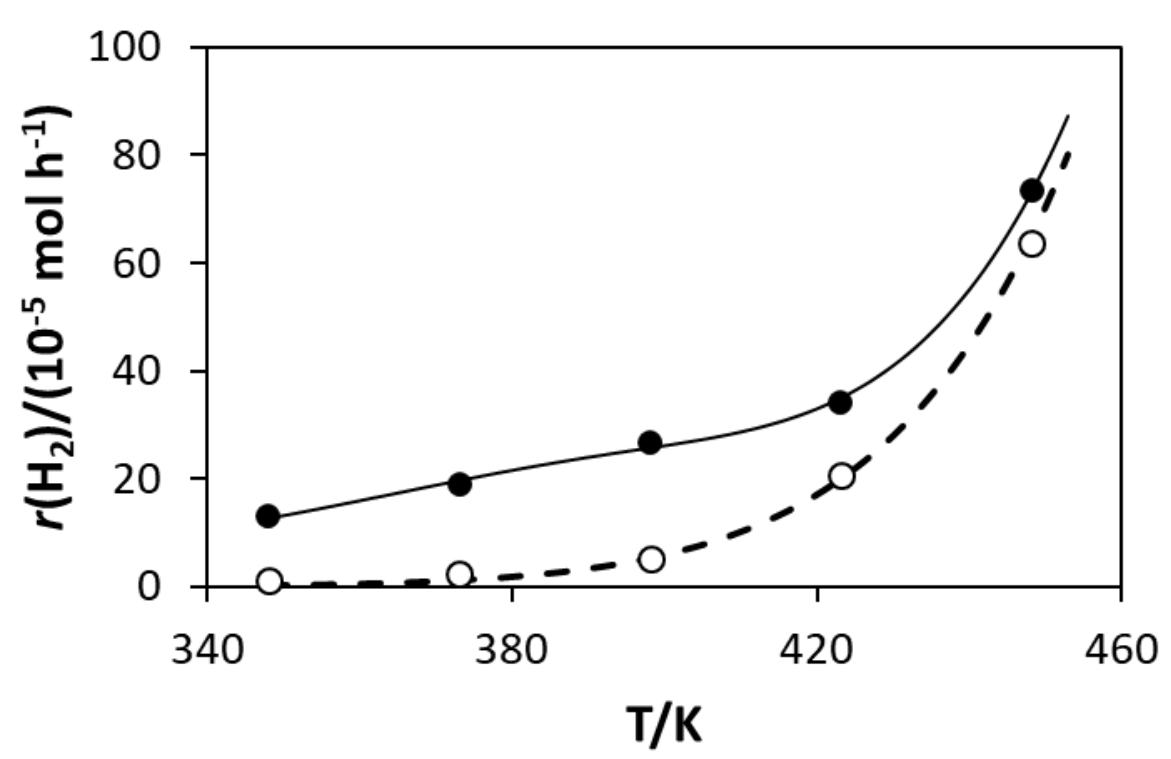

Fig. 5: Plot of $r\left(\mathrm{H}_{2}\right)$ vs temperature for the WGSR thermal (dark) catalysed reaction (open circles) and the photocatalysed reaction (closed circles) by $\mathrm{Au} / \mathrm{TiO}_{2}$. The broken lines represent kinetic model best fits to the data, see Table S2 in S5 in the ESI for fitting constants.

A simple reaction mechanism can be used to interpret these results, in which it is assumed that unoccupied, un-excited reaction sites, S, can mediate reaction (1), via 


$$
\mathrm{S} \stackrel{\mathrm{CO}, \mathrm{H}_{2} \mathrm{O}}{\mathrm{k}_{\mathrm{D}}} \mathrm{CO}_{2}+\mathrm{H}_{2}
$$

where, $k_{D}$ is the dark (thermal) rate constant, whereas the electronically excited unoccupied sites, $\mathrm{S}^{*}$, can mediate reaction (2), via

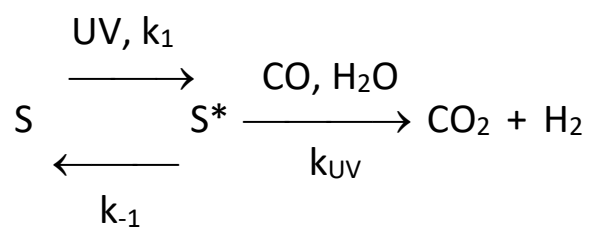

where, $\mathrm{k}_{1}$ and $\mathrm{k}_{-1}$ are the rate constants for the electronic excitation of $\mathrm{S}$ (to $\mathrm{S}^{*}$ ) and the thermal back reaction, respectively, and $k_{u v}$ is the rate constant for the subsequent reaction of $S^{*}$ with the reactants. If $\theta$ is taken as the fraction of $S^{*}$ sites, which obviously will have a very small value, then the individual rates of the thermal and photocatalytic reactions are $r_{D}$ $=\mathrm{k}_{\mathrm{D}}(1-\theta)$ and $r_{\mathrm{uv}}=\mathrm{kuv} \cdot \theta$, respectively, where,

$$
\theta=1 /\left(1+k_{b}+k_{u v}{ }^{\prime}\right)
$$

and $k_{b}=k_{-1} / k_{1}$ and $k_{u v}{ }^{\prime}=k_{u v} / k_{1}$; see section S5 in the ESI, for the derivation of eqn (13). In the absence of UV irradiation, the rate of $\mathrm{H}_{2}$ evolution, i.e. $\mathrm{r}_{\mathrm{D}}$, will be equal to $\mathrm{k}_{\mathrm{D}}$, since $\theta=0$. The measured variation of $k_{D}$ as a function of temperature is illustrated in Fig. 5, and an Arrhenius best line fit to the data, represented by the broken line, reveals values of: $74 \mathrm{~kJ} \mathrm{~mol}^{-1}$ and $3.0 \times 10^{5} \mathrm{~mol} \mathrm{~h}^{-1}$ for the activation energy $\left(E_{a}\right)$ and the pre-Arrhenius factor $(A)$, respectively. For the same system, but under UV irradiation, the overall (i.e. Total) rate of $\mathrm{H}_{2}$ evolution, $\mathrm{r}_{\mathrm{T}}$, is given by the expression:

$$
r_{\mathrm{T}}=r_{\mathrm{D}}+r_{\mathrm{UV}}
$$

where $r_{D}=k_{D} \cdot(1-\theta), r_{U V}=k_{U V} \cdot \theta$, and $\theta$ is defined by eqn (13). If it is assumed that the temperature sensitivities of the rate constants $k_{b}$, kuv' and kuv are, like $k_{D}$, also described by the Arrhenius equation, then it is possible to produce the excellent (solid line) fit to the measured variation of $r_{\mathrm{T}} \mathrm{Vs} \mathrm{T}$, as illustrated in Fig. 5, using optimised fit values of $\mathrm{E}_{\mathrm{a}}$ and $\mathrm{A}$ for $k_{b}$, $k_{u v}$ and $k_{u v}$, as well as the calculated values for $E_{a}$ and $A$ reported above for $k_{D}$. Table S2 in the ESI section lists the optimised values of $E_{a}$ and $A$ used to produce this solid line fit which appear worthy of brief comment. For example, as noted earlier, it seems likely that $\theta$, the fraction of sites that are UV activated will be very small and this appears to be confirmed by the values of $\theta$ calculated as a function of temperature, using eqn (13) and the optimised $E_{a}$ 
(and A) values for $k_{b}$ and kuv' given in Table S2, a plot of which is illustrated in Fig. 6 and reveals a maximum value of $\theta$ of ca. $10^{-6}$.

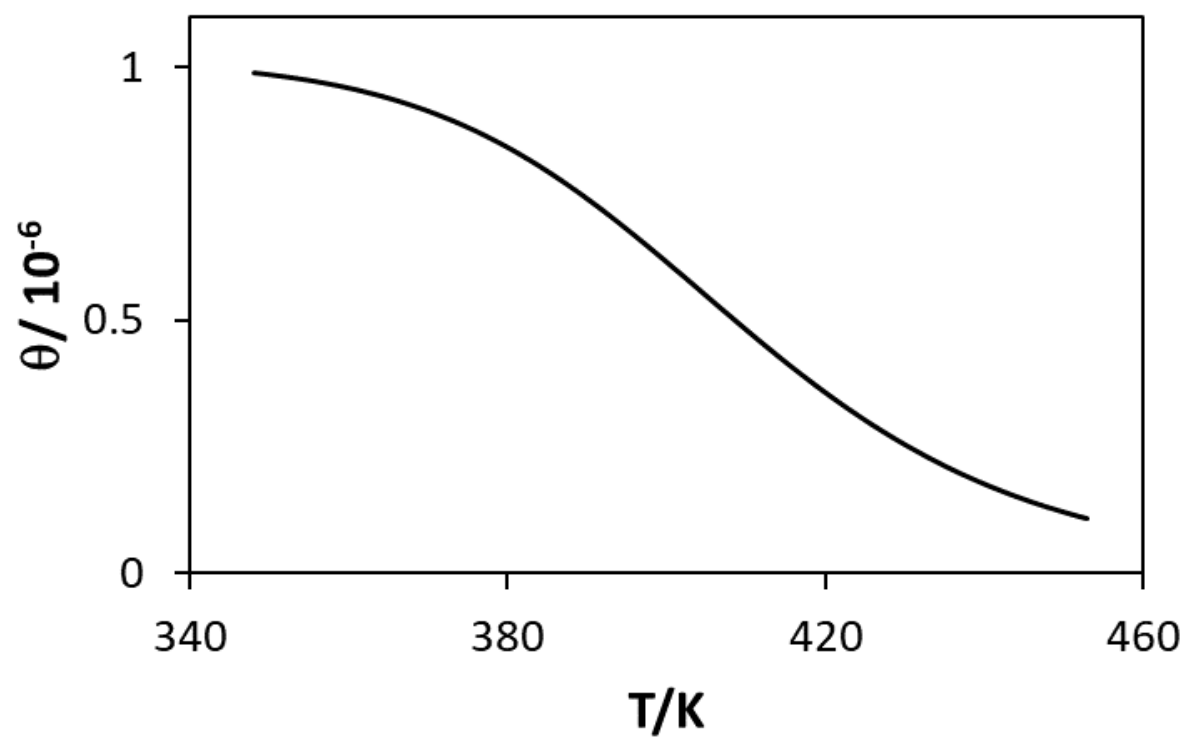

Fig. 6: Plot of $\theta$ vs T, where the values of $\theta$ were calculated using eqn (13) and the optimised $E_{a}$ (and A) values for in Table S2 (5 parameters).

The values of $E_{a}$ and $A$ for the various model rate constants, given in Table S2, allow not only the calculation of the variation of $r_{T}$ as a function of $T$, illustrated by the solid line in Fig. 5 , but also the model predicted variations of the component rates $r_{U v}$ and $r_{D}$ with temperature, the results of which are illustrated in Fig. 7, and show that a significant decrease in $\theta$ above ca. $398 \mathrm{~K}$, illustrated in Fig. 6, produces a marked decrease in $r_{\mathrm{UV}}$, which is not surprising given $r_{\mathrm{UV}}$ $=$ kuv. $\theta$. As a consequence, by ca. $448 \mathrm{~K}$ there is little difference between the rate for the WGSR using $\mathrm{Au} / \mathrm{TiO}_{2}$ in the dark and that when illuminated with UV, because at and above $448 \mathrm{~K}$ the overall rate is dominated by the thermal WGSR. 


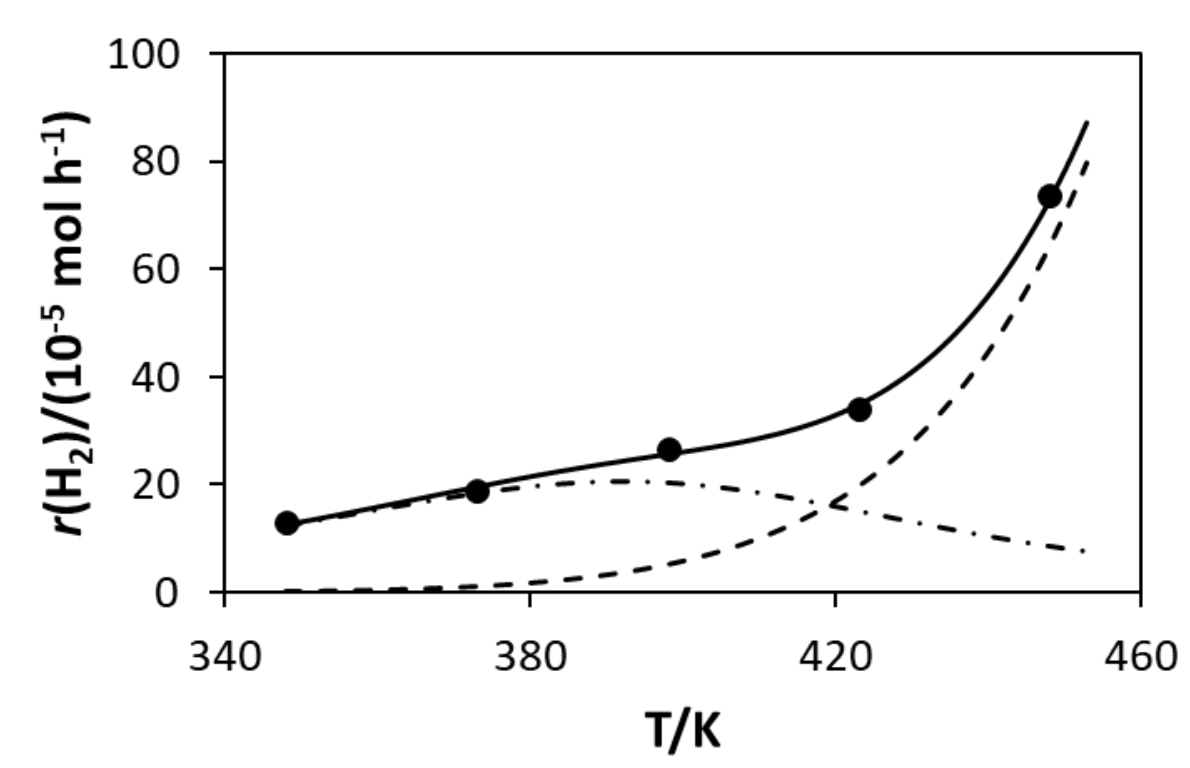

Fig. 7: Plot of $r_{T}$ vs T data points and optimised fits for $r_{T}$ (solid line), $r_{u v}$ (broken dot and dash line) and $r_{\mathrm{D}}$ (dashed line) as a function of $\mathrm{T}$. These optimised fits were calculated using the optimised Arrhenius data for the rate constants $k_{b}$, kuv', kuv and $k_{D}$, given in Table S2, in the ESI and eqns (13) and (14).

Indeed, the plots of the modelled $r_{\mathrm{T}}, r_{\mathrm{Uv}}$ and $r_{\mathrm{D}}$ data suggest that at $348 \mathrm{~K}$, over $98 \%$ of the observed rate for the illuminated $\mathrm{Au} / \mathrm{TiO}_{2}$ system is due to photocatalysis whereas at $448 \mathrm{~K}$ it is $<10 \%$. Figure 7 shows that the peak of the photocatalytic activity is ca. $398 \mathrm{~K}$, i.e. $125^{\circ} \mathrm{C}$, with the rate decreasing at temperatures below and above this temperature, as illustrated by the broken-dotted line. Consequently, $398 \mathrm{~K}$, i.e. $125^{\circ} \mathrm{C}$, was used as the reactor temperature in the studies of the photocatalysed WGSR, i.e. reaction (2), as a function of Au loading and concentrations of $\mathrm{CO}$ and $\mathrm{H}_{2} \mathrm{O}$, which are described below.

\subsection{Au Loading}

The rates of the catalysed and photocatalysed WGS reaction were measured for different $\mathrm{Au}$ wt \% loadings, from $0.01 \mathrm{wt} \%$ to $1 \mathrm{wt} \%$, and the results of this work are illustrated in Fig. 8(a). These results show that the ratio of the total photocatalytic rate, $r_{\mathrm{T}}$, to that of the dark catalytic rate, $r_{\mathrm{D}}$. decreases from 27.7 to 1.2 as the wt\% Au is increased from 0.01 to 1 wt\%. These results indicate that increasing the loading of $\mathrm{Au}$ on the $\mathrm{TiO}_{2}$ enhances the rate of the thermal WGSR significantly; indeed, a plot of $r_{D}$ vs wt\%, illustrated in Fig. 8(b), reveals a good straight line, which suggests that $r_{D}$ is proportional to volume of the Au particles, i.e. 
proportional to $r^{3}$, assuming that the number of Au particles, $N_{p}$, is constant with increasing $w t \% A u$, although it would appear more likely that $r_{\mathrm{D}}$ would be proportional to (wt\% $\left.\mathrm{Au}\right)^{2 / 3}$, if $r_{\mathrm{D}}$ was proportional $r^{2}$. Note also that, not surprisingly, $\mathrm{TiO}_{2}$ on its own is not able to mediate the WGSR either catalytically or photocatalytically.

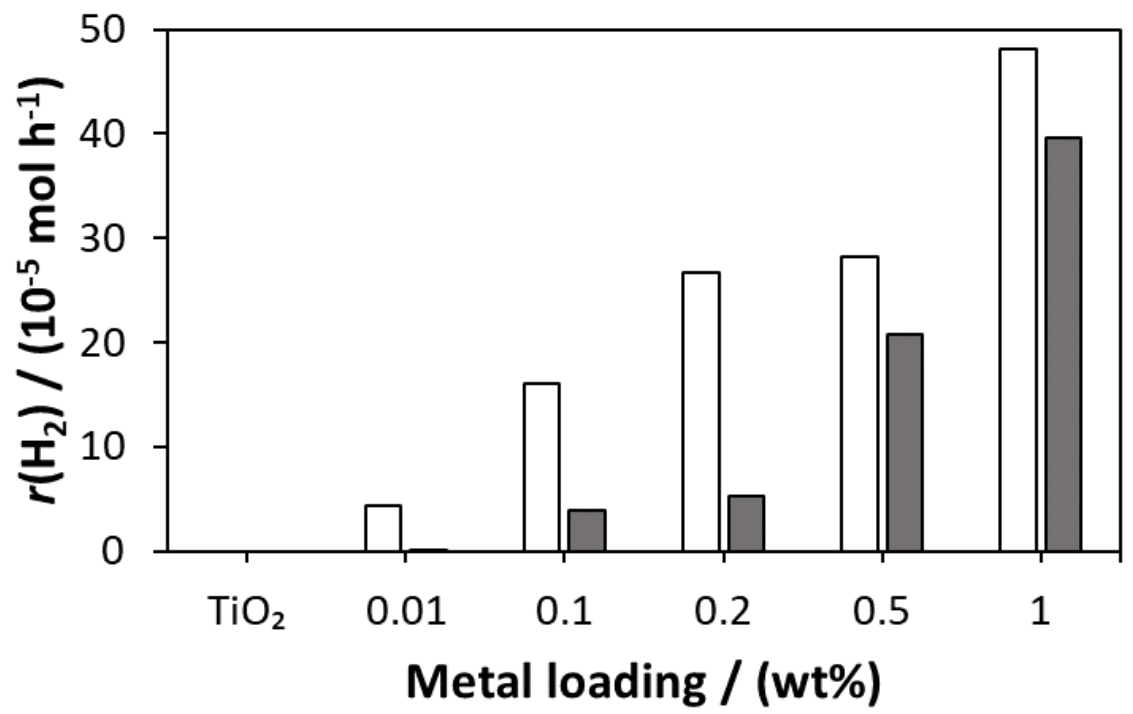

(a)

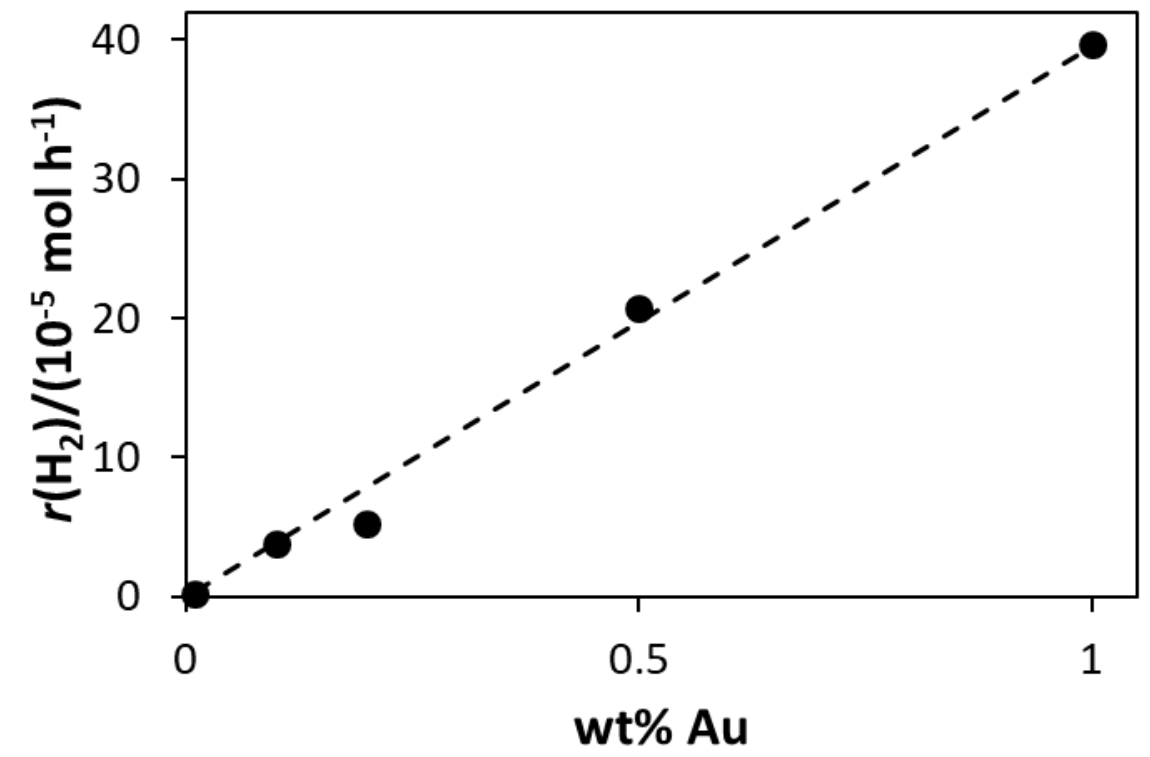

(b)

Fig.8: (a) histogram plot of the measured variation in $r\left(\mathrm{H}_{2}\right)_{1}=r_{\mathrm{T}}$, for the thermal (filled columns; $r_{\mathrm{T}}=r_{\mathrm{D}}$ ) and photocatalysed WGSR (unfilled columns; $r_{\mathrm{T}}=r_{\mathrm{D}}+r_{\mathrm{UV}}$ ) as a function of wt\% of $\mathrm{Au}$ and (b) subsequent plot of the $r\left(\mathrm{H}_{2}\right),=r_{\mathrm{D}}$, data in (a) vs wt\% Au. 
Assuming that $r_{\mathrm{UV}}$ is the difference between $r_{\mathrm{T}}$ and $r_{\mathrm{D}}$, as indicated by eqn (14), then the data in Fig. 8(a) for the photocatalysed WGSR can be used to construct the plot of $\Delta r\left(\mathrm{H}_{2}\right),=r \mathrm{UV}, \mathrm{vS}$ wt\% Au, illustrated in Fig. 9, where $\Delta r\left(\mathrm{H}_{2}\right),=r_{T}-r_{D}=r_{u v}$.

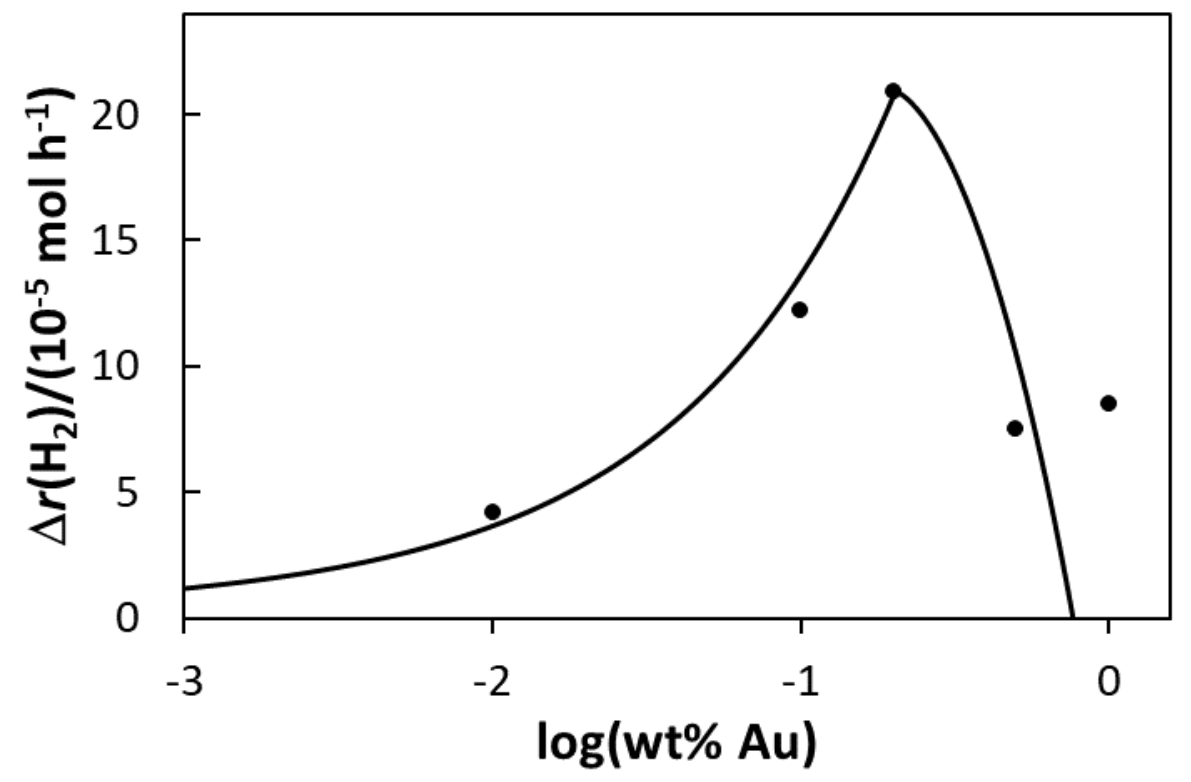

Fig. 9: Plot of $\Delta r\left(\mathrm{H}_{2}\right)$, i.e. $r u v$, vs wt\% Au constructed using the data illustrated in Fig. 8(a). The solid line plot is the best fit to the data based on the EPAO model, using experimentally determined values of the wt\% Au when $r$ of 0.2 and $2 \mathrm{~nm}$, respectively, and $a$ and $b$ optimised fit model constant values of $4 \mathrm{~nm}$ and 22.2, respectively. See S6 in ESI for more model details.

The plot of $r_{U v}$ vs wt\% Au for the photocatalysed WGSR is similar in shape to that generated by Millard and Bowker [15] for the same reaction, but using Pd instead of Au deposited on $\mathrm{P} 25 \mathrm{TiO}_{2}$. As noted earlier, in the latter work, conducted at room temperature, in aqueous solution and in a batch reactor, the rate peaked at a loading of ca. $0.5 \mathrm{wt} \% \mathrm{Pd}$ and was zero at 2 wt\% Pd. As noted by Millard and Bowker [15], the complete lack of photocatalytic activity observed at $2 \mathrm{wt} \% \mathrm{Pd}$ is not due to the UV screening of the $\mathrm{TiO}_{2}$ surface by the $\mathrm{Pd}$ hemispherical particles (with $r=1 \mathrm{~nm}$ ), since a simple calculation shows that a loading of 26.5 wt\%(and not 2 wt\% as found) of such particles as hemispheres would be required to completely cover, and so screen, the surface of the $\mathrm{TiO}_{2}$ through hexagonal packing. Millard and Bowker [15] rationalised this feature, and their measured profile of $r$ vs $\%$ wt Pd, using a model in which each Pd particle is active over a circular boundary region of radius, $r_{z}$, which is much greater (ca. 7 times) than that of the Pd hemisphere particle at its centre, radius, $r$. In this model, the rate is proportional to the number of $\mathrm{Pd}$ particles, $N_{p}$, and the circumference of the boundary. The value of $N_{p}$ is assumed to be a constant, regardless of the wt\% $\mathrm{Pd}$, so 
that as the metal loading is increased so too is the value of $r$ and $r_{z}$ until a maximum rate is reached, when the value of $r_{z}$ is sufficiently large that the boundaries touch. The value of the metal loading at this high point in rate is defined as the wt\%(max) and increasing the metal loading above wt\%(max) results in an increasing degree of boundary overlap, and so loss of boundary perimeter length and a rapid loss in activity.

More recently a revised model of has been reported which appears to better describe the variations in rate observed by Millar and Bowker [15] for the photocatalysed WGSR and those observed by others for the photocatalysed reforming of methanol [23, 24]. In this photocatalytic area and overlap (EPAO) kinetic model [23], the overall rate of reaction is assumed to be proportional to the circular, photocatalytic extended area that surrounds each metal hemisphere, as well as the number of particles, $N_{p}$. The radius of this extended area (or boundary region) is, as before, $r_{z}$, and increases with increasing metal loading. As before, the model predicts a maximum rate will be achieved when the circular areas of activation touch. However, when the metal loading exceeds the value of $\mathbf{w t} \%(\max )$, the areas of activation overlap and produce a loss in photocatalytic activity due to a loss in area of activation. In the EPAO model, the radius of the area of activation, $r_{\mathrm{z}}$, depends directly upon the value of $r$ via the following expression,

$$
r_{\mathrm{z}}=a+b r
$$

where, $a$ and $b$ are two system-dependent constants.

In order to fit the EPAO model to a set of measured rate vs \%wt of $\mathrm{M}$ data, knowledge of just one value of the metal wt\% and its associated value of $r$ (this combination is called a paired data set) is required, since it allows the calculation of the value of $N_{p}$, from which optimised fit to the data values of $a$ and $b$ can be derived. The solid line in Fig. 9 illustrates the EPAO kinetic model optimised fit to the ruv vs wt\% Au data set reported in this study, with the values used to generate this optimised fit given in Table S3 in S6 in the ESI. The model fit to the data illustrated in Fig. 9 appears reasonable, especially at high \%wt\% Au loadings given the likely error in calculating a true value for ruv using eqn (14) since, at these high metal loadings, the value of $r_{\mathrm{T}}$ is close to that of $r_{\mathrm{D}}$.

\subsection{Variation in $\mathrm{CO}$ and $\mathrm{H}_{2} \mathrm{O}$ concentrations}

In all of the work described so far the concentrations of $\mathrm{CO}$ and $\mathrm{H}_{2} \mathrm{O}$ were fixed at 10 vol\% and in the final part of this study the variation in the photocatalytic rate of the WGSR, i.e. ruv, 
where $r_{\mathrm{UV}}=\Delta r\left(\mathrm{H}_{2}\right),=r_{\mathrm{T}}-r_{\mathrm{D}}$, and the thermal rate, i.e. $r_{\mathrm{D}}$, were studied both as a function of [CO] (with $\left[\mathrm{H}_{2} \mathrm{O}\right]$ fixed at 10 vol\%) and $\left[\mathrm{H}_{2} \mathrm{O}\right]$, (with [CO] fixed at 10 vol\%). The results of this work for the photocatalysed WGSR are illustrated in Fig. 10 and reveal that ruv increases sharply as the [CO] is increased from zero to $10 \mathrm{vol} \%$ of $\mathrm{CO}$ and levels off as the [CO] is increased further, whereas, in contrast, over the range 5-20 vol \% of $\mathrm{H}_{2} \mathrm{O}$ at least, $r u v$ is largely independent of $\left[\mathrm{H}_{2} \mathrm{O}\right]$.

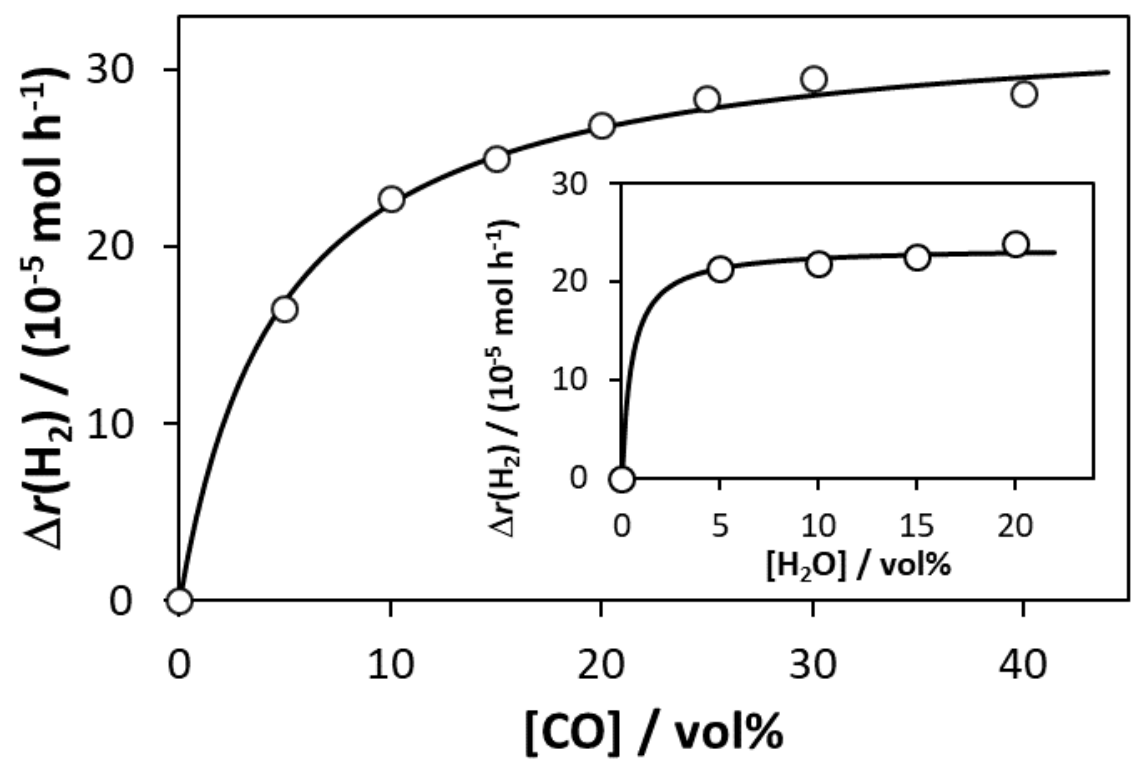

Fig. 10: Plot of $\Delta r\left(\mathrm{H}_{2}\right),=r_{\mathrm{T}}-r_{\mathrm{D}}=r_{\mathrm{UV}}$ for the photocatalysed WGSR, i.e. reaction (2) with $\mathrm{M}=$ $0.2 \mathrm{wt} \% \mathrm{Au}$, as a function of [CO] (with $\left[\mathrm{H}_{2} \mathrm{O}\right]=10 \mathrm{vol} \%$ ) and, in the case of the insert diagram, $\left[\mathrm{H}_{2} \mathrm{O}\right.$ ], (with [CO] $=10$ vol\%). As usual the total flow rate was $10 \mathrm{~cm}^{3} \mathrm{~min}^{-1}$, and reactor temperature $125^{\circ} \mathrm{C}$.

Like many photocatalytic processes [26], the above observed kinetics appear to fit LangmuirHinshelwood kinetics in which the $\mathrm{CO}$ and $\mathrm{H}_{2} \mathrm{O}$ are non-competitively adsorbed, i.e.

$$
r_{\mathrm{UV}}=\frac{\mathrm{k}^{*} \mathrm{~K}^{*}(\mathrm{CO})[\mathrm{CO}]}{1+\mathrm{K}^{*}(\mathrm{CO})[\mathrm{CO}]} \times \frac{\mathrm{K}^{*}\left(\mathrm{H}_{2} \mathrm{O}\right)\left[\mathrm{H}_{2} \mathrm{O}\right]}{1+\mathrm{K}^{*}\left(\left(\mathrm{H}_{2} \mathrm{O}\right)\left[\mathrm{H}_{2} \mathrm{O}\right]\right.}
$$

where $\mathrm{k}^{*}$ is the maximum rate and $\mathrm{K}^{*}(\mathrm{CO})$ and $\mathrm{K}^{*}\left(\mathrm{H}_{2} \mathrm{O}\right)$, the apparent Langmuir adsorption constants for $\mathrm{CO}$ and $\mathrm{H}_{2} \mathrm{O}$, respectively; note the * prefix is used here in order to stress that these constants refer to the photocatalysed WGSR, i.e. reaction (2). The solid lines illustrated in Fig. 10 are the lines of best fit to eqn (16) calculated using values for $\mathrm{k}^{*}, \mathrm{~K}^{*}(\mathrm{CO})$ and $\mathrm{K}^{*}\left(\mathrm{H}_{2} \mathrm{O}\right)$, of $34.7 \times 10^{-5} \mathrm{~mol} \mathrm{~h}^{-1}, 0.21$ (vol\%) $)^{-1}$ and $2(\text { vol\%) })^{-1}$, respectively. It is well known that although most photocatalytic reactions exhibit apparent Langmuir-Hinshelwood kinetics, the mechanism is likely to be much more complex, especially since the Langmuir adsorption 
constants associated with such apparent fits to Langmuir-Hinshelwood kinetics are usually found to be strongly dependent upon irradiance [27-30]. Many of the mechanisms that have been proposed to provide a rationale for the apparent Langmuir-Hinshelwood type kinetics exhibited by photocatalytic systems have been reviewed recently [31], although, as yet, no one mechanism has found universal approval [32].

To our knowledge this is the first study of the kinetics of the photocatalysed WGSR as a function of [CO] and $\left[\mathrm{H}_{2} \mathrm{O}\right]$ and the apparent good fit of the kinetic data illustrated in Fig. 10 to eqn (16), based on non-competitive adsorption Langmuir-Hinshelwood kinetics suggests that the oxidation of the $\mathrm{CO}$ and the reduction of the water occur at two different sites, namely the metal co-catalyst and $\mathrm{TiO}_{2}$ substrate, respectively, which, in turn, is consistent with the flux-matching model of the photocatalytic process described earlier and summarised by reactions (3)-(5).

The kinetics of the thermal (dark) WGSR reaction, i.e. reaction (2), was also studied, i.e. the value of $r D$ measured under the same reaction conditions as above and the results of this work are illustrated in Fig. 11.

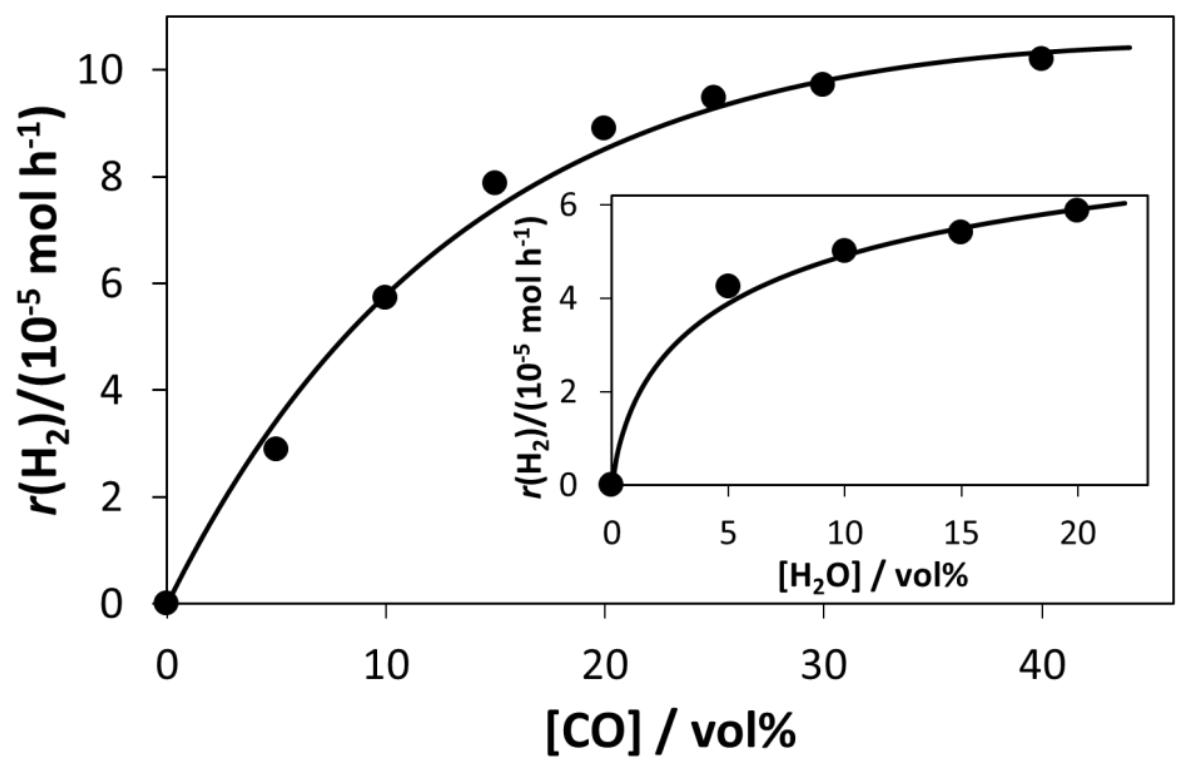

Fig. 11: Plot of $r\left(\mathrm{H}_{2}\right)=r_{\mathrm{D}}$ for the thermal WGSR, i.e. reaction (1) with $\mathrm{M}=0.2 \mathrm{wt} \% \mathrm{Au}$, as a function of $[\mathrm{CO}]$ (with $\left[\mathrm{H}_{2} \mathrm{O}\right]=10$ vol\%) and, in the case of the insert diagram, $\left[\mathrm{H}_{2} \mathrm{O}\right]$, (with $[\mathrm{CO}]=10 \mathrm{vol} \%$ ). As usual the total flow rate was $10 \mathrm{~cm}^{3} \mathrm{~min}^{-1}$, and reactor temperature 125 ${ }^{\circ} \mathrm{C}$.

An initial inspection of these results suggests that, like the photocatalytic reaction, the kinetics might be well described by an apparent Langmuir-Hinshelwood rate equation along 
the lines of eqn (16). However, unlike the photocatalytic WGSR, no common set of values for $k, K(C O)$ and $\mathrm{K}\left(\mathrm{H}_{2} \mathrm{O}\right)$ could be found that provided a good fit to the observed variations in $r_{\mathrm{D}}$ as a function of [CO] and [ $\left.\mathrm{H}_{2} \mathrm{O}\right]$, illustrated in Fig. 11, based on a Langmuir-Hinshelwood kinetic model either with and without competitive adsorption. Not surprisingly, many studies of the kinetics of the thermal WGSR have been carried out previously [32] and several different reaction mechanisms and associated kinetic equations reported, of which the best fit to the kinetic data illustrated in Fig. 11 was found based on kinetic equation derived from a relatively complex reaction mechanism involving intermediate formic acid formation and water adsorption on the supporting substrate and $\mathrm{CO}$ and water dissociative adsorption on the metal, with each adsorption described by a Langmuir type isotherm [33]. Despite its relative complexity, the overall reaction rate equation associated with the model is quite simple, i.e.

$$
r_{\mathrm{UV}}=\frac{\mathrm{kK}(\mathrm{CO})[\mathrm{CO}] \mathrm{K}\left(\mathrm{H}_{2} \mathrm{O}\right)\left[\mathrm{H}_{2} \mathrm{O}\right]}{\left(1+\mathrm{K}(\mathrm{CO})[\mathrm{CO}]+\sqrt{\mathrm{K}\left(\mathrm{H}_{2} \mathrm{O}\right)\left[\mathrm{H}_{2} \mathrm{O}\right]}\right)^{2}}
$$

where $\mathrm{k}$ is the maximum rate and $\mathrm{K}(\mathrm{CO})$ and $\mathrm{K}\left(\mathrm{H}_{2} \mathrm{O}\right)$, are the apparent Langmuir adsorption constants for $\mathrm{CO}$ and $\mathrm{H}_{2} \mathrm{O}$ dissociative adsorption on the metal, respectively. Thus, the solid lines used to fit the data illustrated in Fig. 11 were based on eqn (17) and calculated using values for $\mathrm{K}(\mathrm{CO})$ and $\mathrm{K}\left(\mathrm{H}_{2} \mathrm{O}\right)$, of $0.125(\text { vol\%) })^{-1}$ and $2.8(\text { vol\% })^{-1}$, respectively. Although the values of $\mathrm{K}(\mathrm{CO})$ and $\mathrm{K}\left(\mathrm{H}_{2} \mathrm{O}\right)$ are common for both the main and insert plots illustrated in Fig. 11 , the optimised fit values of $\mathrm{k}$ were slight different namely, $8.0 \times 10^{-5} \mathrm{~mol} \mathrm{~h}^{-1}$ and $9.4 \times 10^{-5}$ $\mathrm{mol} \mathrm{h}^{-1}$, respectively. A summary of the results and calculations reported in this paper is given in Table S4 in section S7 in the ESI.

\section{Conclusions}

$\mathrm{Au} / \mathrm{TiO}_{2}$ is the best of the $\mathrm{M} / \mathrm{TiO}_{2}$ catalysts tested in a gas phase flow system with [CO] and $\left[\mathrm{H}_{2} \mathrm{O}\right]$ at 10 vol\%, where $\mathrm{M}=\mathrm{Au}, \mathrm{Pt}, \mathrm{Pd}$ and $\mathrm{Ag}$, for the thermal (dark) and photocatalytic (UV irradiated) WGSR. Using $\mathrm{Au} / \mathrm{TiO}_{2}$ in the photocatalytic WGSR, the optimum temperature and metal loading are $125^{\circ} \mathrm{C}$ and $0.2 \mathrm{wt} \%$, respectively, whereas in the thermal WGSR, the rate simply increases with increasing temperature and metal loading. The two processes (i.e. the light and dark WGSRs, reactions (1) and (2) respectively, appear competitive, probably due to the utilisation of the same reaction site, with the latter reaction largely supressing the former at high metal loading (> $1 \mathrm{wt} \%$ ) and reaction temperatures (> $448 \mathrm{~K})$. At $125^{\circ} \mathrm{C}$, with a 0.2 wt\% loading, the $\mathrm{Au} / \mathrm{TiO}_{2}$ photocatalyst is very efficient, exhibiting a formal quantum 
efficiency for $1 / 2 \mathrm{H}_{2}$ production of $57 \%$. The kinetics of photocatalytic (UV irradiated) WGSR for the $\mathrm{Au} / \mathrm{TiO}_{2}$ photocatalyst, appear to be those typical for a photocatalytic reaction, exhibiting apparent Langmuir-Hinshelwood kinetics, with the non-competitive adsorption of the $\mathrm{CO}$ and $\mathrm{H}_{2} \mathrm{O}$. The latter feature suggests that the oxidation of the $\mathrm{CO}$ and reduction of the water occur at two different sites, namely the metal co-catalyst and $\mathrm{TiO}_{2}$ substrate, respectively, which in turn is consistent with a flux matching model of the photocatalytic process. The kinetics of thermal WGSR fit the reported [33] rate equation for a more complicated reaction mechanism, involving intermediate formation of formic acid and the adsorption and the dissociative adsorption of $\mathrm{CO}$ and water on the metal, respectively. The use of relatively low temperatures and high photonic efficiencies suggest that a photocatalytic approach to the WGSR may have promise commercially and is worth investigating as such as a scaled-up process. The advantage of the system described here is that it is already of a form (a continuous flow) that is used in industry. In addition, continuous flow industrial photoreactors are not uncommon, particularly in the water purification industry [34] and in industrial organic synthesis (promoting reactions such as chlorinations, sulfonations, sulfoxidations or nitrosylations [35]. The low temperature used in this work $\left(125^{\circ} \mathrm{C}\right)$ also favours its ready scale up, as most industrial photocatalytic reactors are not designed to work at high temperatures. The major problem with scaling-up this system is the cost of the most effective co-catalyst $(\mathrm{Au})$. Thus, further work is required to probe the longevity and recyclability of the $\mathrm{TiO}_{2} / \mathrm{Au}$ photocatalyst and to explore the possible use of Earth-abundant co-catalysts. The fact that $\mathrm{Cu} / \mathrm{ZnO}$ is one of the best low temperature, thermal catalysts for the WGSR is particularly intriguing as $\mathrm{ZnO}$ is a very effective semiconductor photocatalyst. Thus, an investigation of the efficacy of $\mathrm{Cu} / \mathrm{TiO}_{2}$ and $\mathrm{Cu} / \mathrm{ZnO}$ as photocatalysts for the WGSR is an obvious direction of research that should be followed. 


\section{References}

[1] Ammonia Production, https:/ /www. aiche.org/resources/ publications/cep/2016/september/ introduction-ammonia-production, (Accessed Dec. 2020).

[2] National Research Council and National Academy of Engineering, The hydrogen economy: opportunities, costs, barriers, and R\&D needs, National Academies Press, Washington DC, 2004.

[3] J.D. Holladay, J. Hu, D.L. King, Y. Wang, An overview of hydrogen production technologies, Catal. Today, 139 (2009) 244-260.

[4] H. Sakurai, A. Ueda, T. Kobayashi, M. Haruta, Low-temperature water-gas shift reaction over gold deposited on $\mathrm{TiO}_{2}$, Chem. Commun., (1997) 271-272.

[5] N. Ray, V.K. Rastogi, H. Mahapatra, S.P. Sen, Deactivation of low temperature shift catalysis, J. Res. Inst. Catal., 21 (1973) 187-199.

[6] G.K. Reddy, P.G. Smirniotis, Chapter 3 - Low-Temperature WGS Reaction, in: G.K. Reddy, P.G. Smirniotis (Eds.) Water Gas Shift Reaction, Elsevier, Amsterdam, 2015, pp. 47-100.

[7] A. Mills, S. Le Hunte, An overview of semiconductor photocatalysis, J. Photochem. Photobiol. A: Chem., 108 (1997) 1-35.

[8] S.-C. Tsai, Y.-W. Chung, Effects of particle size on photoassisted water-gas shift reaction over $\mathrm{PtTiO}_{2}$, J. Catal., 86 (1984) 231-234.

[9] S.-C. Tsai, C.-C. Kao, Y.-W. Chung, Photoassisted water-gas shift reaction over $\mathrm{PtTiO}_{2}(100)$, J. Catal., 79 (1983) 451-461.

[10] S.M. Fang, B.H. Chen, J. White, Photoassisted water-gas shift reaction on platinized titania. The influence of preparation parameters, J. Phys. Chem, 86 (1982) 3126-3130.

[11] C. Yixuan, W. Zhaobin, C. Yanxin, L. Huaxin, H. Zupei, L. Huiqing, D. Yonglei, Y. Chuying, L. Wenzhao, Metal-semiconductor catalyst: photocatalytic and electrochemical behavior of Pt$\mathrm{TiO}_{2}$ for the water-gas shift reaction, J. Mol. Catal., 21 (1983) 275-289.

[12] S. Sato, J.M. White, Photoassisted water-gas shift reaction over platinized titanium dioxide catalysts, J. Am. Chem. Soc., 102 (1980) 7206-7210.

[13] S. Sato, J.M. White, Photocatalytic water decomposition and water-gas shift reactions over $\mathrm{NaOH}$-coated, platinized $\mathrm{TiO}_{2}$, J. Catal., 69 (1981) 128-139. 
[14] G.K. Reddy, P.G. Smirniotis, Chapter 8 - Photo-Catalytic Water-Gas Shift Reaction, in: G.K. Reddy, P.G. Smirniotis (Eds.) Water Gas Shift Reaction, Elsevier, Amsterdam, 2015, pp. 207223.

[15] L. Millard, M. Bowker, Photocatalytic water-gas shift reaction at ambient temperature, J. Photochem. Photobiol. A: Chem., 148 (2002) 91-95.

[16] F. Sastre, M. Oteri, A. Corma, H. García, Photocatalytic water gas shift using visible or simulated solar light for the efficient, room-temperature hydrogen generation, Energ. Environ. Sci., 6 (2013) 2211-2215.

[17] I. Toyoshima, G.A. Somorjai, Heats of Chemisorption of $\mathrm{O}_{2}, \mathrm{H}_{2}, \mathrm{CO}, \mathrm{CO}_{2}$, and $\mathrm{N}_{2}$ on Polycrystalline and Single Crystal Transition Metal Surfaces, Catal. Rev., 19 (1979) 105-159.

[18] A. Caravaca, H. Daly, M. Smith, A. Mills, S. Chansai, C. Hardacre, Continuous flow gas phase photoreforming of methanol at elevated reaction temperatures sensitised by $\mathrm{Pt} / \mathrm{TiO}_{2}$, React. Chem. Eng., 1 (2016) 649-657.

[19] Flow Chemistry, https:/ /en.wikipedia.org/wiki/Flow_chemistry, (Accessed Dec. 2020).

[20] M. Bowker, D. James, P. Stone, R. Bennett, N. Perkins, L. Millard, J. Greaves, A. Dickinson, Catalysis at the metal-support interface: exemplified by the photocatalytic reforming of methanol on $\mathrm{Pd} / \mathrm{TiO}_{2}$, J. Catal., 217 (2003) 427-433.

[21] J.G. Highfield, M.H. Chen, P.T. Nguyen, Z. Chen, Mechanistic investigations of photodriven processes over $\mathrm{TiO}_{2}$ by in-situ DRIFTS-MS: Part 1. Platinization and methanol reforming, Energ Environ Sci, 2 (2009) 991-1002.

[22] A. Dickinson, D. James, N. Perkins, T. Cassidy, M. Bowker, The photocatalytic reforming of methanol, J. Mol. Catal. A: Chem., 146 (1999) 211-221.

[23] A. Mills, M. Bingham, C. O'Rourke, M. Bowker, Modelled kinetics of the rate of hydrogen evolution as a function of metal catalyst loading in the photocatalysed reforming of methanol by Pt (or Pd)/TiO 2 , J. Photochem. Photobiol. A: Chem., 373 (2019) 122-130.

[24] M. Bingham, A. Mills, Photonic efficiency and selectivity study of $M(M=P t, P d, A u$ and $\mathrm{Ag}) / \mathrm{TiO}_{2}$ photocatalysts for methanol reforming in the gas phase, J. Photochem. Photobiol. A: Chem., 389 (2020) 112257.

[25] J.A. Rodriguez, S. Ma, P. Liu, J. Hrbek, J. Evans, M. Pérez, Activity of $\mathrm{CeO}_{\mathrm{x}}$ and $\mathrm{TiO}_{\mathrm{x}}$ Nanoparticles Grown on Au(111) in the Water-Gas Shift Reaction., Science, 318 (2007) 1757. [26] A. Mills, R.H. Davies, D. Worsley, Water purification by semiconductor photocatalysis, Chem. Soc. Rev., 22 (1993) 417-425. 
[27] A. Mills, J. Wang, The kinetics of semiconductor photocatalysis: Light intensity effects, Z. Phys. Chem., 213 (1999) 49-58.

[28] A. Emeline, A. Salinaro, N. Serpone, Spectral Dependence and Wavelength Selectivity in Heterogeneous Photocatalysis. I. Experimental Evidence from the Photocatalyzed Transformation of Phenols, J. Phys. Chem. B, 104 (2000) 11202-11210.

[29] J.F. Montoya, J.A. Velásquez, P. Salvador, The direct-indirect kinetic model in photocatalysis: A reanalysis of phenol and formic acid degradation rate dependence on photon flow and concentration in $\mathrm{TiO}_{2}$ aqueous dispersions, Appl. Catal. B: Environ., 88 (2009) 50-58.

[30] M.R. Hoffmann, S.T. Martin, W.Y. Choi, D.W. Bahnemann, Environmental applications of semiconductor photocatalysis, Chem Rev, 95 (1995) 69-96.

[31] A. Mills, C. O'Rourke, K. Moore, Powder semiconductor photocatalysis in aqueous solution: An overview of kinetics-based reaction mechanisms, J. Photochem. Photobiol. A: Chem., 310 (2015) 66-105.

[32] R.J. Byron-Smith, M. Loganathan, M.S. Shantha, A Review of the Water Gas Shift Reaction Kinetics, Int. J. Chem. React. Eng., 8 (2010) R4.

[33] D.C. Grenoble, M.M. Estadt, D.F. Ollis, The chemistry and catalysis of the water gas shift reaction: 1. The kinetics over supported metal catalysts, J. Catal., 67 (1981) 90-102.

[34] K. Ewa, R. Sven, Photoreactors for Wastewater Treatment: A Review, Recent Pat. Eng., 4 (2010) 242-266.

[35] Ekato, https:/ /www.ekato.com/en/products/process-plants/photochemical-reactors/, (Accessed Dec. 2020). 